\title{
The Relationship between Students' Approach to Learning and Lifelong Learning
}

\author{
Rita Barros ${ }^{1}$, Angélica Monteiro ${ }^{1}$, Fouad Nejmedinne ${ }^{1}$, José António Moreira ${ }^{2}$ \\ ${ }^{1}$ Instituto Piaget/Universidade Jean Piaget, Praia, Cape Verde \\ ${ }^{2}$ Department of Education and Distance Teaching, Open University, Lisbon, Portugal \\ Email: jmoreira@uab.pt
}

Received July $29^{\text {th }}, 2013$; revised August $31^{\text {st }}, 2013$; accepted October $1^{\text {st }}, 2013$

\begin{abstract}
Copyright (C) 2013 Rita Barros et al. This is an open access article distributed under the Creative Commons Attribution License, which permits unrestricted use, distribution, and reproduction in any medium, provided the original work is properly cited.
\end{abstract}

\begin{abstract}
The current investigation proposes to analyse the relationship between learning, from the appropriation students' make of the different ways of learning and studying, and their willingness to be involved in lifelong learning (LL) activities. The theoretical rationale is inscribed in the Biggs' Theory (1987), concerning the student's approach to learning, and under the guiding principle of LL. The concept of LL has been understood and formalised in a distinct way, translated into different educational policies, the practices of which must be empirically supported. We present a correlational study, with a sample of 163 Higher Education students. The approaches to learning were supported by the revised two-factor study process questionnaire (R-SPQ-2F). To evaluate the involvement of students in LL activities, the contents of some items of the Lifelong Learning Questionnaire (Kirby, Knapper, Lamon, \& Egnatoff, 2010) were used. The results obtained in the correlational analysis allow us to associate the deep approach to some characteristics of learners throughout their life, especially concerning the establishing of goals and the self-direction of learning, whereas the superficial approach is mainly associated with the adaptation of learning strategies. The practical implications of these results are discussed below.
\end{abstract}

Keywords: Higher Education; Learning Styles; Lifelong Learning

\section{Introduction}

Learning is one of important themes explored in the multiple theoretical perspectives of Psychology. Our research focuses on learning in adulthood, whose characteristics involve particular cognitive and motivational aspects that seem interesting to some areas of psychology. Cognitive Psychology (Sternberg \& Grigorenko, 2000), Educational Psychology and Developmental Psychology (Smith \& Pourchot, 1998) are good examples. At same time, several authors in the area of Education, specifically those focused on the Education of youngsters and adults, seek to understand the study processes and learning concepts of these students (Biggs, 1987, 1993; Entwistle \& Ramsden, 1983).

Biggs, Kember and Leung (2001), based on the model presage-process-product (3P), have developed a more simplified version of the instrument student process questionnaire (Biggs, 1987) for the understanding of study processes and approaches to learning, the revised two-factor study process questionnaire (R-SPQ-2F).

This instrument evaluates the relationship between student characteristics and education context, their approach to learning tasks and learning results. The approach to learning, according to the authors (idem: 135), can be superficial, deep or high performance and involve different motivations and strategies.

In this article, we seek to relate the different approaches to learning in higher education students and their willingness to become involved in Lifelong Learning (LL) activities.

LL, understood as a paradigm emerging within the context of a society of knowledge and information, offers the possibility of looking at educational phenomena in a different way, and has facilitated the emergence of a frame of mind valuing the learning accomplished by people within personal, social and professional fields (Pires, 2007).

Lifelong Learning, simultaneously translating into a political agenda and a research field, requires a reflection focused on this articulation. The contributions of research on this subject, with an impact on political processes and learning practices, must offer a critical analysis of their social contextualization, as well as possible projections of what Lifelong Learning could become (Preece, 2011; UNESCO, 2010), considering that the future of Lifelong Learning still holds important ambiguities and questions (Jarvis, 2010).

\section{Theoretical Frame of Reference}

\section{Approaches to Higher Education Learning}

Biggs et al. (2001) present a systemic version of the students' approaches to learning, through the Presage-Process-Product (3P) model. Within this model, results may influence the approaches to tasks, and these may influence the context of education and the factors more directly related to students.

According to Biggs (1987), the main differentiating factor of learning results is not the cognition ability but the using of different study processes depending on "approaches to learning". These approaches can be classified as superficial, deep and stra- 
tegic or high-performance.

The superficial approach concerns an attitude based on the "minimum possible effort", that is, when faced with learning, the student is not interested in understanding it or developing it (...). This approach is, therefore, reproductive and marked by extrinsic motivation and fear of failure.

The deep approach is oriented by the intention of the student to face in depth the task or the content to be learned. For that, high level cognition abilities are used, such as syntheses, analyses, comparisons and confrontations, and even the cultural and cognitive repertoire is used, helping these students to achieve a transforming and creative level.

The strategic or high-performance approach is based on the intention of obtaining the maximum efficiency or the best classifications through the intrinsic motivations of the subject.

\section{Lifelong Learning}

The approach to the paradigm of Lifelong Learning guides the discourses and educational practices of today, based on the policies of the three main intergovernmental organizations with activities in this field, namely the Council of Europe, the United Nations Educational, Scientific and Cultural Organization (UNESCO) and the Organization for Economic Cooperation and Development (OECD). In fact, the problematization of lifelong learning has been constant in the last few decades, and its discursive and operational translation, in terms of educational policies, has been marked by diversity and discontinuity. Whereas the programmes of the Council of Europe and UNESCO are based on universal values of peace, equality, interculturality, diversity and human rights, that is, a humanistic view of education, OECD, because of its nature and history, has focused on education's economic benefits and potential and its functionalist side (Centeno, 2011).

The experience of UNESCO and the European Union shows that the general goals defined by international organizations have been globally ignored by the educational systems of different countries, but also allows us to conclude that statistical goals, seen as monitoring indications, do not guarantee the achievement of objectives by those same educational systems (Jallade, 2011).

In conclusion, Lifelong Learning has tensions and contradictions, with consequences on political choices, educational practices and theoretical-scientific priorities.

\section{Method}

\section{Objectives}

Our study has a quantitative, correlational and cross-cutting nature, and its main goal is to understand the relationship of approaches to learning with age and the tendency/inclination to become involved in LL activities.

Considering that lifelong learner's characteristics involves establishment of goals, application of knowledge and skills, self-direction and evaluation, location of information and adaptation of learning strategies (Knapper \& Cropley, 2000), our hypothesis is that exists a positive and significant relationships between those characteristics and deep learning approach.

\section{Participants}

The sample is constituted by 163 students from higher edu- cation, 37 males $(22.7 \%)$ and 126 females $(77.3 \%)$. Most of the respondents $(89.6 \%)$ attend first cycle studies, granting a university degree, $6.7 \%$ attend Master's and $3.7 \%$ attend post-graduations. The average age is 26.6 years, with a standard deviation of 8.7, a minimum age of 18 and a maximum of 61 . Regarding the area of training, 97 of the cohort are in Education (59.5\%), 62 in Health (38\%) and 4 are in other areas (2.5\%). With respect to the employment situation, 83 are exclusively students $(50.9 \%)$ and 77 are working students $(47.2 \%)$. Three of the respondents $(1.8 \%)$ claim to be in another situation.

The sampling technique was non-probabilistic and, as such, students were selected by convenience, particularly by easy accessibility, being guaranteed anonymity and the individual confidentiality of the results.

\section{Instruments}

The survey is split into three parts. The first part focuses on social-demographic aspects, namely age, gender, education level, education area (Education/Health) and professional status. This section also includes a question about the perception students have about their academic performance, categorized according to the ECTS classification scale, inscribed in the European Credit Transfer System, supporting the Bologna Declaration (DGES, s/d).

In the second part of the survey, in order to evaluate the involvement of students in LL activities, we were inspired by 10 of the 14 items included in the Lifelong Learning Questionnaire, by Kirby, Knapper, Lamon, \& Egnatoff (2010). The items used are based on the lifelong characteristics of the learner, defined by Knapper and Cropley (2000), namely the establishing of goals, the application of knowledge and skills, self-direction and evaluation, search for information and adaptation to learning strategies. According to the authors, the scale evaluates the tendency/inclination of adults to LL, which results from the combination of prematurely defined features and situational factors taking place at a later stage, making it necessary to focus on those features and situations and realize how they can be manipulated in a desirable sense. The items are evaluated in a 5-point Likert-type scale, from "I completely disagree" (-2) to "I completely agree" $(+2)$.

The approaches to learning were evaluated in the third part of the survey by the Portuguese translation of the Brazilian-validated scale Revised two-factor Study Process Questionnaire (R-SPQ-2F, performed by Godoy (2009). In this validation for the Portuguese language, the original scale was initially subject to translation and retro-translation processes. Its final version is constituted by 20 items, evaluated in a 5-point Likert-type scale, from "never" (1) to "always" (5), grouped in 4 sub-scales: deep motivation, deep strategy, superficial motivation and superficial strategy. There is a linear, positive and significant correlation between deep motivation and deep strategy and between superficial motivation and superficial strategy (moderate and low, respectively). Low linear, negative and statistically significant correlations are found between deep and superficial motivation and between deep and superficial strategy.

The values of internal consistency, evaluated by Cronbach's alpha, are compatible with those in the original scale, regarding deep approach $(\alpha=.76)$, and even superior regarding superficial learning $(\alpha=.74)$. The internal consistency and validity of criteria reveal the good psychometric qualities of the instrument. The same may be said about the construct validity, supported 
by the confirmatory factor analysis, performed according to the Structural Equation Model (SEM). Thus, the structure of the reviewed version shows two non-hierarchical factors, distinguishing the deep approach from the superficial approach, each of them comprised by ten items. The results of this validation meet the results of exploratory and confirmatory factor analysis carried out in other studies, namely in Spain (Justicia, Pichardo, Cano, Berbén, \& De la Fuente, 2008) and reveal a very satisfactory adjustment in view of the original model.

Given the above, it seemed suitable to use this instrument in the Portuguese language in order to evaluate the approaches to learning in Higher Education students.

\section{Procedures}

The items in the Lifelong Learning Questionnaire (Kirby, Knapper, Lamon, \& Egnatoff, 2010) were selected according to the following requirements:

- 2 items for each characteristic of the learner throughout his/her life, according to Knapper and Cropley (2000), given that the characteristics with less items integrate precisely two;

- a balance in the number of items per characteristic;

- the easiness in terms of fulfilment of the linguistic and cultural equivalents underlying the Portuguese translation.

Concerns regarding the linguistic and cultural equivalence have supported the Portuguese translation of the Brazilian-validated scale Revised two-factor Study Process Questionnaire (R-SPQ-2F)

After defining the data collection survey, the students were asked to complete the online questionnaire, being guaranteed anonymity and the individual confidentiality of the results.

\section{Analysis of Data}

The statistical analysis was performed through the SPSSStatistical Package for the Social Sciences-version 19.0, and the procedures were accomplished through inferential statistics. The correlational analyses were performed based on Pearson's linear correlation coefficient. All results were considered statistically significant for a confidence interval of $95 \%$ (Marôco \& Bispo, 2005).

\section{Findings}

\section{Relationship between Approaches to Learning and Age}

Pearson's coefficient points to a negative $(r=-.173)$ and statistically significant $(p=.027)$ correlation between deep learning and age, indicating that, as age progresses, students in higher education are less likely to resort to deep learning. There isn't a significant correlation between age and superficial learning.

The adoption of a more superficial strategy by students as age progresses may, once again, be related to the multiplicity of roles performed by older students.

The social demands associated with young adults are distinct from those they face in a mature adulthood (Erikson, 1963), with implications in terms of investment in the different tasks and consequent time management.

These results differ from those presented by Biggs and Kirby (1983), since these authors show that pre-university students reveal lower levels of deep approach, when compared with university students. However, this difference in results can be justified by the social-cultural and historical context of the students involved.

\section{Relationship between Approaches to Learning and LL}

Table 1 shows the statistically significant correlations between the approaches to learning and the items relating to the characteristics of the learner throughout his life, defined by Knapper and Cropley (2000), namely:
A) Establishment of goals
B) Application of knowledge and skills
C) Self-direction and evaluation
D) Location of information
E) Adaptation of learning strategies

\section{Relationship between Approaches to Learning and the Establishing of Goals}

Table 1 shows a positive correlation between the statement "I love learning for its own sake" and deep learning, in its motivational and strategic components.

In students who love "to learn for its own sake" (item 9), deep learning involves not only intrinsic motivation, aimed at learning for its own sake, but also the examination of strategic processes to be implemented. If students do not identify extrinsic reinforcement, they also miss this perception, which justifies their negative correlation with the superficial strategy.

On the other hand, for students who show a deep learning, focusing on details does not invalidate the existence of a macroscopic vision of the learning content. Nevertheless, it implies a more detailed strategy, and therefore more developed in its analysis, translating into the positive correlation with the deep strategy. Valadares and Moreira (2009) support this idea as they articulate the processes of progressive differentiation and integrative or inclusive reconciliation with significant learning.

\section{Relationship between Approaches to Learning and Application of Knowledge and Skills}

The attribution of meaning, evaluated by item 5, implies the articulation and coherence between the countless information and knowledge supporting deep learning. This articulation is only possible by resorting to deep strategies.

The negative correlation between the articulation of new subjects to be learned from previous knowledge (item 12) and deep motivation, combined with the positive correlation with superficial motivation and strategy, can be explained by the understanding students have of it. In fact, it is possible that students showing deep motivation understand the relationship with previously acquired subjects as a limitation to the exploration of new contents. On the other hand, this relationship may be seen as a learning strategy to be maximised, especially when the investment in the learning task is limited and when the student is more focused on the results than on the learning processes, or on the learning itself.

\section{Relationship between Approaches to Learning and Self-Direction and Evaluation}

Learning evaluation can be combined with issues of auto- 
Table 1.

Correlations between LL and the approaches to learning and its dimensions (motivational and strategic).

\begin{tabular}{|c|c|c|c|c|c|c|c|}
\hline & \multirow{2}{*}{ Lifelong Learning (LL) } & \multicolumn{6}{|c|}{ Student's Approach to Learning (SAL) } \\
\hline & & DL & $\mathrm{DM}$ & DS & SL & SM & SS \\
\hline \multirow[b]{2}{*}{ A } & I love learning for its own sake & $.375^{* * *}$ & $.186^{*}$ & $.406^{* * *}$ & & $-.158^{*}$ & \\
\hline & $\begin{array}{l}\text { When I learn something new, I try to focus } \\
\text { on the details rather than on the "big picture" }\end{array}$ & $.312^{* * *}$ & & $.350^{* * *}$ & & & \\
\hline \multirow{2}{*}{ B } & I am able to impose meaning upon what others see as disorder & $.188^{*}$ & & $.254^{* *}$ & & & \\
\hline & When I approach new material, I try to relate it to what I already know & $-.18^{*}$ & & $-.223^{* *}$ & $.318^{* * *}$ & $.204^{* *}$ & $.246^{* *}$ \\
\hline \multirow{2}{*}{ C } & I feel others are in a better position than I am to evaluate my success as a student & $-.183^{*}$ & & $-.267^{* *}$ & $.347^{* * *}$ & $.31^{* * *}$ & $.261^{* *}$ \\
\hline & It is my responsibility to make sense of what I learn at school & & & $.206^{* *}$ & & $-.186^{*}$ & \\
\hline \multirow{2}{*}{ D } & I try to relate academic learning to practical issues & $.309^{* * *}$ & $.16^{*}$ & $.329^{* * *}$ & & & \\
\hline & I often find it difficult to locate information when I need it & & & & $.318^{* * *}$ & $.247^{* *}$ & $.274^{* * *}$ \\
\hline \multirow{2}{*}{$\mathrm{E}$} & I can deal with the unexpected and solve problems as they arise & & & & $.256^{* *}$ & $.265^{* *}$ & $.157^{*}$ \\
\hline & I feel uncomfortable under conditions of uncertainty & & & $-.208^{* *}$ & $.344^{* * *}$ & $.34^{* * *}$ & $.227^{* *}$ \\
\hline
\end{tabular}

Note: ${ }^{*} p<.05,{ }^{* *} p<.01,{ }^{* * *} p<.001$.

nomy, self-direction and self-regulation. The positive correlation found between favouring hetero-evaluation and superficial learning, both from motivational and strategic points of view, implies external attributions.

By delegating on others responsibility to evaluate (item 8) success in learning, students may, in case of failure, build defence mechanisms for the protection of the self (Fontaine, 1990). For students with a deep approach to learning, the issue of the evaluation only arises on a strategic level, as revealed by the negative correlation observed. Causal attributions (internal or external) justify, not only the learning evaluation, but also the responsibility it entails (item 13).

In this regard, Biggs et al. (2001) mention that teaching and evaluation methods often encourage the superficial approach, if not properly aligned with the education objectives.

\section{Relationship between Approaches to Learning and Location of Information}

Table 1 shows a positive correlation between the deep approach (motivation and strategy) and the statement "I try to relate academic learning to practical issues". On the other hand, we find a negative correlation between the superficial approach (motivation and strategy) and the statement "I often find it difficult to locate information when I need it".

Students investing in learning in a developed way transfer "articulately the thinking strategies used in a given context, as well as other knowledge generated from these, to others. Transference is the basis of knowledge accumulation and human learning, especially determining the possibility of, from what is already known (contents, strategies, abilities, etc.), articulating it in another way, reaching new solutions, conclusions and ideas" (Davis, Nunes, \& Nunes, 2005: p. 210). Therefore, they relate academic learning to practical matters (item 10). This concern demands not only an intrinsic motivation in learning, but also strategies that facilitate the relationship mentioned.

Deep investment in learning causes transversal skills to develop, mainly the abilities of information selection, analysis, synthesis. The development of these skills facilitates the search for information supporting the learning process. Thus, it is understood that students with a superficial approach (both from motivational and strategic points of view), not having the opportunity to develop these skills, share a perception of difficulty in finding information when they need it (item 11).

\section{Relationship between Approaches to Learning and Adaptation of Learning Strategies}

The positive correlation between the superficial approach and the statement "I can deal with the unexpected and solve problems as they arise" can be explained by the fact that in superficial approach the investment of the student is smaller.

In this context, we realize that the student builds a self-perception of the ability to deal with the unexpected (item 3 ), even if the result of its action is debatable, or even inappropriate. In fact, by focusing on the results of the learning, procedural and methodological matters, which ensure safety in the action, these matters end up not being considered as very important.

Concerning item 4, discomfort facing uncertainty situations, this is positively correlated with superficial learning and negatively correlated with deep strategy.

If, in deep approach, uncertainty can be a challenge to the adoption of deep learning strategies, in superficial approach it is common for students to face situations in which they are unsure about the efficiency of their knowledge and skills in order to solve these situations.

"Feeling comfortable dealing with uncertainty" is directly related to metacognitive processes, such as, the decision making process in extremely complex situations, very common today, in which there is a dynamic and constantly changing environment (Rosenhead \& Mingers, 2001).

\section{Conclusion and Recommendations}

With the purpose of analysing the different approaches to learning among higher education students and their willingness to be involved in LL activities, we have conducted this comparative and correlational study. 
More specifically, the goals of this study were as follows: 1) to compare how students seize the different ways of learning and studying according to their perception of academic performance, training area and professional status (student versus working student), and 2) to know the relationships between approaches to learning and age and tendency/inclination to become involved in LL activities.

Regarding the comparison between the approaches to learning and the students' characteristics, we see that the main differences, where applicable, concern the strategies used. Whereas the approaches are not distinguished according to the perception of the academic performance, the strategic dimension differs according to the training area and professional status of the student.

Concerning the relationship between the approaches to learning and age, in our study, the older students tend to resort to more superficial approaches, particularly in their strategic component. It seems, as mentioned above, that this result can be explained by the demands of daily life and the assuming of simultaneous tasks for which fast and efficient solutions are required.

There is yet another important factor to consider, as mentioned by Bigg et al. (2001): the teaching strategies and evaluation methods can force the students to choose strategies inscribed in a superficial approach.

As for the relationship between the approaches to learning and the tendency/inclination for students to become involved in LL activities, this was grouped according to the lifelong characteristics of the learner, namely: establishment of goals; application of knowledge and skills; self-direction and evaluation; location of information and adaptation of learning strategies.

Concerning the establishment of goals, the love of learning for its own sake, positively correlated with deep learning, is related to the intrinsic motivation and emotional value the subject confers to the learning itself. In turn, the ability to articulate a macroscopic vision of learning contents with the details demanded by deep learning reveals operational skills far beyond the instrumentality of the know-how.

Regarding the application of knowledge and skills, there is a tendency for the superficial approach to "maximise" already developed knowledge and skills in the resolution of new challenges.

Concerning self-direction and evaluation, the choice for more superficial approaches is related to the responsibility of the other. In the case of students investing in deep learning, there is greater individual control, which translates into self-regulated learning. This learning includes mental processes and learning strategies, in which students become deliberately involved to improve their learning and their performance. The sensed selfcompetence and autonomy, the orientation for the task and the learning environment in the classroom interfere with the intrinsic motivation.

Location of information is a skill which depends on how it is selected and accessed, as well as on the ability to relate the learning to practical matters. We see that the students likely to show a superficial approach find it more difficult to locate information. This is a cross-cutting skill, just like the application of knowledge in solving practical problems, which, as a whole, constitutes a "common denominator existing either in acquired knowledge beyond subjects and areas or in cognitive activities of learning" (Pacheco, 2011: p. 49).

Finally, concerning the adaptation of learning strategies, we see that students who tend to adopt a superficial approach seem to be more able to deal with the unexpected, although they feel uncomfortable in situations of uncertainty, contrary to what was shown in the strategic dimension of deep learning.

Studying the relationships between approaches to learning and some lifelong characteristics of the learner has allowed us to equate some possible practical implications for the formal contexts of higher education, which we will now mention:

- Considering that superficial and deep learning are not mutually exclusive or deterministic, it becomes the job of the educational agents to promote a context facilitating significant learning, characteristic of a more deep approach. In this sense, Biggs et al. (2001) mention that the presence of a more superficial approach may indicate that something is wrong with the teaching and evaluation methods chosen by the teachers (Biggs et al., 2001).

- The stimulus to the establishment of relationships and resignification of contents, inherent to deep learning, is essential to the implementation of transferences. This transference enables to "deliberately extend abilities and postures into other scenarios, helping students to think about their ideas, articulating them with those conveyed in other subjects, and applying them in both school and non-school contexts" (Davis, Nunes, \& Nunes, 2005: p. 210) where LL activities are included.

- The "I love learning for its own sake" is not necessarily a pre-determined condition. The cyclic model of the "3P" exemplifies the interdependence of every element comprising the teaching and learning process. This way, by promoting an environment conducive to learning, the teacher is able to gradually inspire this love and stimulate the autonomous processes of discovery, typical of a self-regulated learning.

- This plasticity to be experienced within a formal context in higher education may reflect in the willingness shown by students to become involved in activities throughout their lives. From this point of view, educating higher education students and guiding them towards deep approaches can represent a significant contribution to this purpose.

- Responding to challenges imposing on today's society, lifelong learning becomes imperative.

\section{REFERENCES}

Biggs, J., Kember, D., \& Leung, D. Y. (2001). The revise two-factor study process questionnaire: R-SPQ-2F. British Journal of Education Psychology, 71, 133-149.

http://dx.doi.org/10.1348/000709901158433

Biggs, J. (1993). From theory to practice: A cognitive systems approach. Higher Education Research and Development, 12, 73-86. http://dx.doi.org/10.1080/0729436930120107

Biggs J. B. (1987). Student approaches to learning and studying. Australian council for educational research. Hawthorn: Victoria.

Biggs, J. B., \& Kirby, J. R. (1983). Approaches to learning in universities and CAEs. Vestes, 27, 3-9.

Centeno, V. (2011). Lifelong learning: A policy with a long past but a short history. International Journal of Lifelong Education, 30, 133150. http://dx.doi.org/10.1080/02601370.2010.547616

Davis, C., Nunes, Marina, M. R., \& Nunes, C. A. A. (2005). Metacognição e sucesso escolar: Articulando teoria e prática. Cadernos de Pesquisa, 35, 205-230. http://dx.doi.org/10.1590/S0100-15742005000200011

DGES (2013). ECTS: European credit transfer system. http://tinyurl.com/bfbkqpv

Entwistle, N. (2010). Taking stock: An overview of key research find- 
ings. In J. Christensen Hughes, \& J. Mighty (Eds.), Taking stock: Research on teaching and learning in higher education (pp. 15-57). Montreal and Kingston: McGill-Queens University Press.

Entwistle, N., \& Ramsden, P. (1983). Understanding student learning. London: Croom Helm.

Erikson, E. (1963). Childhood and society. New York: WW Norton \& Company.

Fontaine. A. M. (1990). Motivação e realização escolar. In B. P. Campos (Ed.), Psicologia do desenvolvimento e da educação de Jovens (pp. 93-132). Lisboa: Universidade Aberta.

Garrison, D. (1997). Self-directed learning: Toward a comprehensive model. Adult Education Quarterly, 48, 18-33.

http://dx.doi.org/10.1177/074171369704800103

Godoy, S. (2009). Validação para o Brasil da escala revised two-factor study process questionnaire (R-SPQ-2F). Ph.D. Thesis, São Paulo: São Paulo University.

Jallade, J.-P. (2011). International approaches to education: A review of some major cooperative programmes. European Journal of Education, 46, 7-24. http://dx.doi.org/10.1111/j.1465-3435.2010.01469.x

Jarvis, P. (2010). Inquiry journal of lifelong education. International Journal of Lifelong Education, 29, 397-400.

http://dx.doi.org/10.1080/02601370.2010.488802

Justicia, F., Pichardo, M., Cano, F., Berben, A., \& De la Fuente, J. (2008). The revised two factor study process questionnaire (R-SPQ$2 \mathrm{~F})$ : exploratory and confirmatory factor analyses at item level. European Journal of Psychology of Education, 23, 355-372. http://dx.doi.org/10.1007/BF03173004

Kirby, J., Knapper, C., Lamon, P., \& Egnatoff, W. (2010). Development of a scale to measure lifelong education. International Journal of Lifelong Education, 29, 291-302. http://dx.doi.org/10.1080/02601371003700584

Knapper, C. K., \& Cropley, A. (2000). Lifelong learning in higher education. London: Kogan Page.
Marôco, J., \& Bispo, R. (2005). Estatística aplicada às ciências sociais e humanas. Lisboa: Climepsi.

Pacheco, J. (2011). Discursos e lugares das competências em contexto de educação e formação. Porto: Porto Editora.

Pires, A. (2007). Reconhecimento e validação das aprendizagens experienciais. Sísifo/Revista de Ciências da Educação, 2, 5-19.

Preece, J. (2011). Research in adult education and lifelong learning in the era of CONFINTEA VI. International Journal of Lifelong Education, 30, 99-117. http://dx.doi.org/10.1080/02601370.2011.538180

Rosenhead, J., \& Mingers, J. (2001). Rational analysis for a problematic world: problem structuring methods for complexity, uncertainty and conflit. West Sussex: John Willey \& Sons.

Smith, M., \& Pourchot, T. (1998). Adult learning and development: Perspectives from educational psychology. NJ: Lawrence Erlbaum Associates.

Sternberg, R. (2009). Cognitive psychology (5th ed.). Belmont: Wadsworth.

Sternberg, R., \& Grigorenko, E. (2000). Teaching for successful intelligence. Arlington Heights, IL: Skylight.

UNESCO (2010). Relatório global sobre aprendizagem e educação de adultos. Brasília: Instituto da UNESCO para a Aprendizagem ao Longo da Vida (UIL).

Vasconcelos, R., Almeida, L., \& Monteiro, S. (2005). Métodos de estudo em alunos do $1^{\circ}$ ano da universidade-métodos de estudo na Universidade. Psicologia Escolar e Educacional, 9, 195-202. http://dx.doi.org/10.1590/S1413-85572005000200002

Valadares, J., \& Moreira, M. (2009). A teoria da aprendizagem significativa: Sua fundamentação e implementação. Coimbra: Almedina.

Young, M. (2005). The motivational effects of the classroom environment in facilitating self-regulated learning. Journal of Marketing Education, 27, 25-40. http://dx.doi.org/10.1177/0273475304273346 